\title{
Papers
}

\section{Inhibition of serotonin reuptake by antidepressants and upper gastrointestinal bleeding in elderly patients: retrospective cohort study}

\author{
C van Walraven, M M Mamdani, P S Wells, J I Williams
}

\begin{abstract}
Objectives To determine the association between inhibition of serotonin reuptake by antidepressants and upper gastrointestinal bleeding.

Design Retrospective cohort study from population based databases.

Setting Ontario, Canada.

Participants 317824 elderly people observed for more than 130000 person years. The patients started taking an antidepressant between 1992 and 1998 and were grouped by how much the drug inhibited serotonin reuptake. Patients were observed until they stopped the drug, had an upper gastrointestinal bleed, or died or the study ended.

Main outcome measure Admission to hospital for acute upper gastrointestinal bleeding.

Results Overall, 974 bleeds were observed, with an overall bleeding rate of 7.3 per 1000 person years. After controlling for age or previous gastrointestinal bleeding, the risk of bleeding significantly increased by $10.7 \%$ and $9.8 \%$, respectively, with increasing inhibition of serotonin reuptake. Absolute differences in bleeding between antidepressant groups were greatest for octogenarians (low inhibition of serotonin reuptake, 10.6 bleeds/ 1000 person years $v$ high inhibition of serotonin reuptake, 14.7 bleeds/ 1000 person years; number needed to harm 244) and those with previous upper gastrointestinal bleeding (low, 28.6 bleeds / 1000 person years $v$ high, 40.3 bleeds $/ 1000$ person years; number needed to harm 85).

Conclusions After age or previous upper gastrointestinal bleeding were controlled for, antidepressants with high inhibition of serotonin reuptake increased the risk of upper gastrointestinal bleeding. These increases are clinically important for elderly patients and those with previous gastrointestinal bleeding.
\end{abstract} serotonin reuptake inhibitors decrease serotonin uptake from the blood by platelets. Because platelets do not synthesise serotonin, these inhibitors decrease the amount of serotonin in platelets. ${ }^{2}$ Case reports sug-

\section{Introduction}

Serotonin potentiates platelet aggregation. ${ }^{1}$ Selective gest that serotonin reuptake inhibitors are associated with a variety of bleeding events. ${ }^{3-10}$

The strongest evidence linking the use of selective serotonin reuptake inhibitors with bleeding comes from a case-control study. ${ }^{11}$ The authors identified 1651 incident cases of upper gastrointestinal bleeding or ulcer perforation from a high quality clinical database and randomly selected 10000 controls matched by age, sex, and time. ${ }^{12}{ }^{13}$ Drug records were reviewed to determine if the participants had been exposed to selective serotonin reuptake inhibitors or other antidepressants. After potential confounders were controlled for, the odds of gastrointestinal bleeding for users of the inhibitors were three times that of the controls. Patients taking tricyclic antidepressants had no increased risk of upper gastrointestinal bleeding.

The study did, however, have potential limitations. ${ }^{14-17}$ Firstly, if the hypothesised pathophysiology of bleeding involved the inhibition of serotonin reuptake, the extent of this inhibition should correlate with the risk of bleeding and determine how these drugs were grouped. ${ }^{14}$ Yet the antidepressant groups comprised drugs with often disparate inhibition. $.^{14} \mathrm{Sec}-$ ondly, the association between the inhibitors and gastrointestinal bleeding could have been due to confounding. This is because patients with depression generally are sicker than those without. ${ }^{18-24}$ Patients who are sicker are more likely to experience gastrointestinal bleeding because such bleeding has been associated with factors that contribute to overall disease burden, including increased age, decreased physical activity, heart failure, diabetes, and annual number of hospital admissions. ${ }^{25-27}$ Thirdly, as only 131 bleeds were recorded in the antidepressant group, there were relatively wide confidence intervals for bleeding risks. Fourthly, serotonin plays a minor part in the haemostatic process. It is a comparatively weak agonist for platelet aggregation because its stimulation of platelet receptors induces change only in platelet shape and not the platelet secretory processes key to platelet activation.$^{28}$ Finally, the study could not provide the absolute risk of serious bleeding associated with antidepressant use. Clinicians need this information when choosing antidepressants for patients.

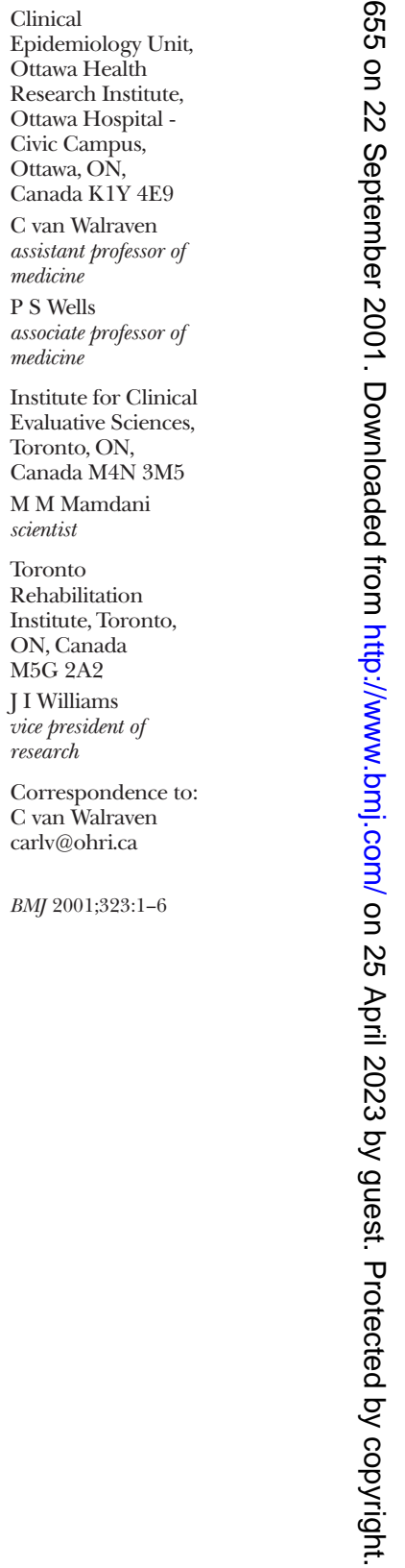


To address these issues, we conducted a retrospective cohort study to determine the overall risk of serious upper gastrointestinal bleeding in elderly patients taking antidepressants. We also aimed to determine if this risk varied with the extent of inhibition of serotonin reuptake by antidepressants.

\section{Patients and methods}

\section{Cohort definition}

We obtained our data from administrative databases for Ontario, Canada, where services provided by physicians, drugs, and hospital services for patients aged over 65 are provided by a universally funded health programme. The databases are anonymous and linked by unique identifiers for patients that are common to all databases.

We used a retrospective cohort design that included all residents of Ontario aged over 65 who received a new prescription for any antidepressant (see table A1 in appendix). Age was determined from the registered patient database, which contains basic personal information on all residents of Ontario. Drug use was determined from the Ontario drug benefits database, which records the type of drug, quantity, and date of all prescriptions for all residents aged 65 and over. Because regulations stipulate that prescriptions should not exceed three months, we reviewed all drug claims between 1 April 1992 and 1 July 1992 to ensure that study patients were not receiving an antidepressant. We also excluded those without a valid health insurance plan number.

\section{Patient observation}

We began our surveillance on 1 July 1992. Patients entered the cohort on the date they were first prescribed an antidepressant (see table A1). Patients were grouped by the affinity of the antidepressant for the transporter responsible for serotonin reuptake. This affinity was categorised before the analysis as low, intermediate, or high, on the basis of the drug's dissociation constant. ${ }^{2.9}$

Observation ended when exposure to the drug, as defined by the duration of the prescription, ended. Prescription duration equalled drug quantity (from the Ddug benefits database) divided by the daily intake of drug recommended by the manufacturer. ${ }^{30}$ Drug exposure was considered to have continued as long as a subsequent prescription for the antidepressant, or others in the same group, was filled within 30 days of the prescription's duration. For example, assume that we calculated a prescription to end on 1 January. Exposure to the drug continued beyond that date only if the patient filled a subsequent prescription for that antidepressant, or another in the same group, by 30 January. Otherwise exposure ended on 1 January.

Observation also ended when patients were admitted to hospital with upper gastrointestinal bleeding, or died or the study ended. Admissions to hospital with the primary diagnosis of upper gastrointestinal bleeding were identified from the discharge abstract database. This database records all admissions to Ontario hospitals, and major diagnoses are classified by using ICD-9 (international classification of diseases 9th revision) codes. By using a database similar to the discharge abstract database, one study found that the
ICD-9 codes 533 (complicated gastric ulcer), 532 (uncomplicated duodenal ulcer), 533 (complicated peptic ulcer), 578.0 (haematemesis), 579.0 (melaena), and 578.9 (unspecified intestinal bleeding) had a positive predictive value of $86 \%$ for upper gastrointestinal bleeds. ${ }^{31}$ We used these codes to identify upper gastrointestinal bleeds in our study. Patient deaths were identified from the registered patient database, which records all deaths for residents of Ontario, including those occurring out of the province. Our study ended 1 April 1998.

\section{Potential confounders}

We controlled for factors that are associated with upper gastrointestinal bleeding. These included age and sex. We considered medical conditions, including previous upper gastrointestinal bleeding and diabetes. ${ }^{27}{ }^{32}$ Patients were classified with gastrointestinal bleeding if the discharge abstract database indicated that they were admitted to hospital with a primary diagnosis of upper gastrointestinal bleeding (see table A2 in the appendix) before entering the study. Patients were classified with diabetes if the Ontario drug benefits database indicated that they were prescribed oral hypoglycaemics or insulin before the end of observation. Confounding drugs included non-steroidal anti-inflammatory drugs, acetylsalicylic acid, glucocorticoids, anticoagulants, $\mathrm{H}_{2}$ blockers, and proton pump inhibitors. We considered that patients were exposed to these drugs if they were prescribed within 30 days of the end of observation. From 1996, elderly patients had to pay the first $\$ 100$ of their prescriptions. Therefore capture of non-steroidal anti-inflammatory drugs and acetylsalicylic acid that can be acquired without prescription is likely to be incomplete.

Finally, given the long duration of our study and the potential for changes in patient care over that time, we thought it necessary to control for year of study entry. To do this we stratified the analysis by year of entry to the study.

\section{Analysis}

To adjust for varying observation times, we calculated the density of incidence of upper gastrointestinal bleeding for each group. We compared rates between strata by using relative rates and $95 \%$ confidence intervals. ${ }^{33}$ Notable differences between groups were expressed as the number needed to harm. We calculated this as the reciprocal of the differences between the bleeding rates of the two groups, expressed as proportions.

To test for trend in bleeding rates across groups for serotonin reuptake inhibition after controlling for potential confounders, we used a weighted linear regression method. ${ }^{34}$ In this analysis the bleeding rates based on larger numbers of cases are given more weight. The stratified analysis models the natural log of bleeding rates as a linear function of serotonin reuptake inhibition (see table A1) within each strata of the confounding variable, and then combines the equations to derive an overall estimate of the common coefficient for the inhibition group. One minus the antilog of the common coefficient for the inhibition group expresses the relative change in bleeding rates for each group with higher inhibition of serotonin reuptake. This analysis assumes that the effect of inhibition is the same within each strata. This was an 
appropriate assumption after inspection of the rates within each strata (table 1).

We repeated the analysis with proportional hazards modelling (SAS, version 6.12). This modelled observation time as a function of the inhibition group and the covariates listed in table 1 . As in the original analysis, observation began when patients started antidepressants and finished when they stopped treatment, or died, the study ended, or they had an upper gastrointestinal bleed. To test for the assumption of proportionality, we recreated the model with an interaction term between time and each of the covariates in the model. ${ }^{35}$ Due to computational rigours of this latter analysis, we conducted it on a randomly selected subset of the dataset that contained $30 \%$ of the original cohort. We tested the assumption of proportionality independently for each covariate.

\section{Results}

During the study period, 383911 of 1798382 (21.3\%) elderly patients were prescribed antidepressants. Of these, $317824(82.8 \%)$ started their drug during the study period and were included. They were observed for 132812 person years, during which time there were 974 admissions to hospital for upper gastrointestinal bleeding. Table 2 describes the cohort. Patients entering the study in later years were much more likely to be prescribed antidepressants with greater inhibition of serotonin reuptake.

The overall risk of upper gastrointestinal bleeding was 7.3 per 1000 person years (table 1). The risk of upper gastrointestinal bleeding was significantly associated with each confounder. This was especially so with increasing age and previous upper gastrointestinal bleeding.

The risk of upper gastrointestinal bleeding increased slightly with inhibition of serotonin reuptake, rising from 6.6 bleeds per 1000 person years for antidepressants with the lowest inhibition to 7.9 bleeds per 1000 person years in the highest group (table 1). This trend did not reach significance.

However, significant increases in upper gastrointestinal bleeding with increasing inhibition were seen after controlling for variables strongly associated with upper gastrointestinal bleeding (table 1). When we controlled for age, the risk of bleeding increased by $10.7 \%$ for each higher inhibition group. For octogenarians, bleeding rates increased from 10.6 per 1000 person years in the lowest group to 14.7 per 1000 person years in the highest group. This corresponded with a number needed to harm of 244-that is, one extra upper gastrointestinal bleed would be expected when 244 patients were treated with an antidepressant from the high rather than the low serotonin reuptake inhibitors. When we controlled for previous upper gastrointestinal bleeding, bleeding risk increased by $9.8 \%$. For patients with a history of active peptic ulcer disease, bleeding rates increased from 28.6 per 1000 person years in the lowest group to 40.3 per 1000 person years in the highest group. This corresponded with a number needed to harm of 85 . Finally, we also found a period effect. When we controlled for the year of study entry, the relative risk of upper gastrointestinal bleeding increased significantly by $10.7 \%$ with increasing inhibition of serotonin reuptake.
Table 1 Rates of gastrointestinal bleeding per 1000 person years of observation in antidepressant groups by serotonin reuptake inhibition. Values in brackets are $95 \%$ confidence intervals

\begin{tabular}{|c|c|c|c|c|c|}
\hline \multirow[b]{2}{*}{ Factor or stratum } & \multirow[b]{2}{*}{ Cohort } & \multicolumn{3}{|c|}{ Antidepressant group } & \multirow{2}{*}{$\begin{array}{c}\% \text { increase in bleeding } \\
\text { with increased serotonin } \\
\text { inhibition }\end{array}$} \\
\hline & & Low & Intermediate & High & \\
\hline Cohort & 7.3 & 6.6 & 7.4 & 7.9 & $9.2(-3.7$ to 23.9$)$ \\
\hline \multicolumn{6}{|l|}{ Study entry: } \\
\hline 1992 & 6.2 & 5.4 & 6.7 & 8.4 & \multirow{4}{*}{10.7 (4.6 to 17.2$)$} \\
\hline $1993-5$ & 7.3 & 7.0 & 8.3 & 6.8 & \\
\hline $1995-7$ & 6.9 & 6.5 & 6.7 & 7.2 & \\
\hline $1997-8$ & 8.5 & 7.5 & 7.2 & 9.5 & \\
\hline
\end{tabular}

Relative risk

Patient factors

Age:

\begin{tabular}{lrrrr}
\hline $65-70$ & 4.1 & 3.9 & 4.2 & 4.1 \\
\hline $70-75$ & 7.2 & 7.5 & 6.6 & 7.3 \\
\hline $75-80$ & 8.8 & 6.4 & 11.5 & 8.6 \\
\hline$>80$ & 12.3 & 10.6 & 11.1 & 14.7
\end{tabular}

Relative risk 3.0 (2.6 to 3.6$)$

Sex:

\begin{tabular}{lccrrr}
\hline Sex: & & & & & \\
\cline { 1 - 4 } Female & 6.0 & 5.7 & 6.0 & 6.3 & \multirow{2}{*}{$7.6(-1.6$ to 17.7$)$} \\
\hline Male & 10.0 & 8.6 & 10.5 & 10.8 & \\
\hline Relative risk & $1.7(1.5$ to 1.9$)$ & & & &
\end{tabular}

Medical history

Diabetes:

\begin{tabular}{|c|c|c|c|c|c|}
\hline No & 7.0 & 6.3 & 7.2 & 7.5 & \multirow{2}{*}{$7.1(-2.1$ to 17.2$)$} \\
\hline Yes & 9.1 & 8.9 & 8.4 & 9.9 & \\
\hline Relative risk & $1.3(1.1 \mathrm{to}$ & & & & \\
\hline \multicolumn{6}{|c|}{ Previous gastrointestinal bleeding: } \\
\hline No & 6.7 & 6.1 & 6.8 & 7.1 & \multirow{2}{*}{$9.8(0.3$ to 20.0$)$} \\
\hline Yes & 33.2 & 28.6 & 29.1 & 40.3 & \\
\hline
\end{tabular}

Drugs

Non-steroidal anti-inflammatory drugs:

\begin{tabular}{|c|c|c|c|c|c|}
\hline No & 6.4 & 5.8 & 6.2 & 7.0 & \multirow{2}{*}{$6.6(-2.5$ to 16.7$)$} \\
\hline Yes & 17.9 & 16.7 & 17.4 & 19.3 & \\
\hline
\end{tabular}

\begin{tabular}{|c|c|c|c|c|c|}
\hline Relative risk & $28(24$ to 33$)$ & & & & \\
\hline \multicolumn{6}{|c|}{ Acetylsalicylic acid: } \\
\hline No & 7.0 & 6.3 & 7.1 & 7.5 & $4.5(-4.4$ to 14.3$)$ \\
\hline Yes & 11.6 & 11.8 & 10.7 & 12.2 & \\
\hline Relative risk & 1.7 (1.4 to 2.0$)$ & & & & \\
\hline \multicolumn{6}{|l|}{ Alucocorticoids: } \\
\hline No & 7.2 & 6.5 & 7.2 & 7.8 & \multirow{2}{*}{$8.9(-0.4$ to 19.2$)$} \\
\hline Yes & 12.2 & 9.6 & 15.7 & 11.2 & \\
\hline Relative risk & 1.7 (1.2 to 2.3 ) & & & & \\
\hline \multicolumn{6}{|l|}{ Anticoagulant: } \\
\hline No & 7.1 & 6.3 & 7.2 & 7.6 & \multirow{2}{*}{$-0.4(-9.0$ to 8.9$)$} \\
\hline Yes & 15.4 & 17.3 & 14.3 & 14.9 & \\
\hline Relative risk & 2.2 (1.7 to 2.8$)$ & & & & \\
\hline \multicolumn{6}{|c|}{ eptic ulcer treatment: } \\
\hline No & 6.3 & 5.6 & 6.4 & 6.8 & \multirow{2}{*}{$7.8(-1.5$ to 17.9$)$} \\
\hline Yes & 12.9 & 12.0 & 12.4 & 14.1 & \\
\hline Relative risk & 2.1 (1.8 to 2.4$)$ & & & & \\
\hline
\end{tabular}

Relative risks compare bleeding risk in bottom stratum with that of top stratum. Final column presents relative change in risk of gastrointestinal bleeding when switching to next higher serotonin blocking group.

Proportional hazards modelling gave similar results (see table A2). After all potential confounders were controlled for, increasing inhibition of serotonin reuptake was associated with a significantly increased risk of upper gastrointestinal bleeding (risk ratio 1.1, 1.02 to 1.19 ). The two analyses yielded similar results because six of the univariate relative risks lay within the $95 \%$ confidence intervals of corresponding estimates in the multivariate Cox model (table 2). In this analysis there is no period effect. Of all covariates in the final model (see table A2), only anticoagulation had a significant interaction with time. We kept the Cox 
Table 2 Description of cohort and antidepressant groups by serotonin reuptake inhibition. Values are numbers (percentages) of patients unless stated otherwise

\begin{tabular}{|c|c|c|c|c|}
\hline \multirow[b]{2}{*}{ Factor } & \multirow[b]{2}{*}{$\begin{array}{c}\text { Cohort } \\
(\mathrm{n}=317824)\end{array}$} & \multicolumn{3}{|c|}{ Antidepressant group } \\
\hline & & $\begin{array}{c}\text { Low } \\
(\mathrm{n}=76 \mathrm{712})\end{array}$ & $\begin{array}{c}\text { Intermediate } \\
(\mathrm{n}=139 \text { 715) }\end{array}$ & $\begin{array}{c}\text { High } \\
(\mathrm{n}=101397)\end{array}$ \\
\hline Median (interquartile range) observation period (months) & $1.6(0.7-4.3)$ & $1.9(1.0-5.6)$ & $1.0(0.4-2.6)$ & $2.1(1.0-6.5)$ \\
\hline Upper gastrointestinal bleed during study & $974(0.3)$ & $276(0.4)$ & $294(0.2)$ & $404(0.4)$ \\
\hline \multicolumn{5}{|l|}{ Year of study entry: } \\
\hline 1992 & 28782 (9.1) & 11098 (14.5) & $13396(9.6)$ & $4288(4.2)$ \\
\hline $1993-5$ & $92071(30.5)$ & $27133(24.3)$ & $46564(33.3)$ & $23324(23.0)$ \\
\hline $1995-7$ & $93967(29.6)$ & $19874(35.4)$ & $40937(29.3)$ & $33156(32.7)$ \\
\hline $1997-8$ & 98054 (30.9) & $18607(25.9)$ & $38818(27.8)$ & $40629(40.1)$ \\
\hline \multicolumn{5}{|l|}{ Patient factors: } \\
\hline Mean (SD) age (years) & $74.5(7.5)$ & $75.1(7.8)$ & $74.1(7.2)$ & $74.7(7.6)$ \\
\hline Female & $205894(64.8)$ & $48089(62.7)$ & $93473(66.9)$ & $64332(63.4)$ \\
\hline \multicolumn{5}{|l|}{ Medical history: } \\
\hline Diabetes & $41913(13.2)$ & 9467 (12.3) & $19233(13.8)$ & $13213(13.0)$ \\
\hline Upper gastrointestinal bleeding & $7420(2.3)$ & $1804(2.4)$ & $3184(2.3)$ & $2432(2.4)$ \\
\hline \multicolumn{5}{|l|}{ Drug use: } \\
\hline Non-steroidal anti-inflammatory drugs & $32269(10.2)$ & $6824(8.9)$ & $17900(12.8)$ & $7545(7.4)$ \\
\hline Acetylsalicylic acid & $23118(7.3)$ & $5465(7.1)$ & $10311(7.4)$ & $7342(7.2)$ \\
\hline Steroids & $9351(2.9)$ & $2204(2.9)$ & $4363(3.1)$ & $2784(2.7)$ \\
\hline Anticoagulants & $8437(2.7)$ & $2002(2.6)$ & $3176(2.3)$ & $3529(3.2)$ \\
\hline Peptic ulcer treatment ${ }^{\star}$ & 45335 (14.3) & $10660(13.9)$ & 19936 (14.3) & $14739(14.5)$ \\
\hline
\end{tabular}

*Includes $\mathrm{H}_{2}$ receptor antagonists and proton pump inhibitors.

model because this interaction was of borderline significance $(\mathrm{P}=0.03)$ and the point estimate was of questionable clinical significance (risk ratio 1.001).

\section{Discussion}

We found a trend towards an increased risk of upper gastrointestinal bleeding for patients taking antidepressants with greater inhibition of serotonin reuptake. This association was significant when we controlled for age or previous upper gastrointestinal bleeding. We believe that the increased bleeding rates are clinically important for octogenarians or patients with previous upper gastrointestinal bleeding and should be considered when selecting antidepressants. For most patients, however, such precautions are probably unnecessary.

Our conclusions are similar to those of de Ajabo et al, ${ }^{11}$ despite some notable differences between our studies. Firstly, increased overall illness is associated with both depression ${ }^{18-24}$ and gastrointestinal bleeding. ${ }^{25-27}{ }^{36}$ The large size of our study allowed us to remove potential confounding from this association by restricting the analysis to patients taking antidepressants. Secondly, our study contained a different collection of drugs because it included venlaflaxine, nefazodone, and bupropion but not dothiepin, citalopram, lofepramine, and mianserin. Additionally, as has been suggested, ${ }^{14}$ we categorised antidepressants on the basis of their inhibition of serotonin reuptake rather than their structure. Finally, our study took place in a different healthcare system with an older patient population. Our findings corroborate those of de Ajabo et al in a distinct patient population using a different study design. We believe that this strengthens the association between inhibition of serotonin reuptake by antidepressants and gastrointestinal bleeding.

Octogenarians and patients with previous upper gastrointestinal bleeding are at especially high risk from antidepressants with high inhibition of serotonin reuptake. ${ }^{25}$ It is possible that increased bioavailability of selective serotonin reuptake inhibitors in elderly patients results in a stronger antiplatelet effect at the same dose, thereby increasing the risk of gastrointestinal bleeding. These findings might also be a function of particular vulnerability to gastrointestinal bleeding in elderly patients ${ }^{26}$ and those with previous upper gastrointestinal bleeding, thereby allowing the antiplatelet effect of the antidepressant to become apparent. These factors would explain why the association between bleeding risk and inhibition of serotonin reuptake was seen only after these strong confounders were controlled for.

Two factors could explain why upper gastrointestinal bleeding was associated with inhibition of serotonin reuptake after the year of study entry was controlled for (table 1). Firstly, the number of octogenarians who were prescribed antidepressants with high inhibition increased from 892 in 1992 to 11179 in 1997. Secondly, the use of upper endoscopy in elderly patients increased noticeably during the study. Whereas rates for upper endoscopy for patients aged between 65 and 70 years in Ontario decreased from 28.3 per 1000 population in 1992 to 23.7 per 1000 in 1998, rates for octogenarians increased from 23.7 to 30.4 per 1000 during the same period. Therefore major changes during the study in the bleeding risk of patients taking selective serotonin reuptake inhibitors and the use of an important technology to diagnose upper gastrointestinal bleeds may explain the cohort effect in our base analysis. No cohort effect was, however, found in our multivariate proportional hazards model (see table A2).

We believe that our study is valid and provides new information that is useful to clinicians. It is population based and includes a large number of participants. This increased the precision of point estimates for bleeding rates and allowed us to limit the analysis to patients taking antidepressants. It also allowed us to measure absolute differences in bleeding risks, which are essential for determining clinical relevance. The validity of 


\section{What is already known on this topic}

A case-control study found that the risk of upper gastrointestinal bleeding increases with intake of antidepressants that extensively inhibit serotonin reuptake

The study's validity was questioned because antidepressants were not specifically classified by the extent that they inhibit serotonin reuptake, and absolute differences in bleeding rates between antidepressants were unavailable

\section{What this study adds}

The risk of upper gastrointestinal bleeding in elderly and depressed patients increases with antidepressants having the greatest extent of inhibition of serotonin reuptake

This increased risk of bleeding is clinically important for patients with a high risk of bleeding-namely, octogenarians and those with previous upper gastrointestinal bleeding

The extent that an antidepressant inhibits serotonin reuptake should be considered when drugs are required for depression in high risk patients

our methods to calculate bleeding rates is supported by our rates being similar to those in two other cohort studies. ${ }^{26}{ }^{37}$ Although drug exposure was measured by prescription only, this method agrees well with self reported use of drugs. ${ }^{38}$ Our study outcome of admission to hospital with upper gastrointestinal bleeding was explicitly determined by using diagnostic codes that are highly indicative of such bleeding.

Our results potentially have two minor limitations. Firstly, although we controlled for important confounders, we did not control for all of the factors that de Ajabo et al considered, such as smoking or "antecedents of upper gastrointestinal disorders." Because the independent risks of bleeding associated with these factors were not provided, ${ }^{11}$ we are unsure of the importance of their control when studying upper gastrointestinal bleeding. Secondly, we considered only upper gastrointestinal bleeds that resulted in admission to hospital. We may therefore have missed those patients whose bleed resulted in death before admission to hospital or that did not require admission. This problem is common to many studies with admission to hospital for gastrointestinal bleeding as an outcome. ${ }^{11} 262732363739$ Despite this potential misclassification bias ${ }^{40}$ we found a significant association between the inhibition of serotonin reuptake and gastrointestinal bleeding when important confounders were controlled for.

Depressed patients have a higher risk of gastrointestinal bleeding when taking antidepressants with higher inhibition of serotonin reuptake. For high risk patients, such as octogenarians and those with previous gastrointestinal bleeding, we believe that the differences are clinically important and should be considered when antidepressants are selected. Further study is required to determine if serotonin blockade increases the risk of gastrointestinal bleeding as well as the risk of other clinical bleeds in other patient populations. In contrast, it needs to be determined whether the antiplatelet effects of antidepressants are beneficial for patients at high risk of thromboembolic disorders.

We thank Dr George Wells and Dr Peter Austin for statistical advice. $\mathrm{CvW}$ was an Arthur Bond scholar of the Physicians Services Foundation and is an Ontario Ministry of Health career scientist. PSW is a scientist of the Medical Research Council.

Contributors: $\mathrm{CvW}$ conceived the study; he will act as guarantor for the paper. CvW, MMM, PSW, and JIW contributed to the design, analysis, and interpretation of the data. $\mathrm{CvW}$ drafted the paper, and all investigators helped revise the paper.

Funding: None.

Competing interests: None declared.

\section{Appendix}

Table A1 Antidepressants available in Ontario drug benefit programme and their categorisation on basis of drug's affinity for serotonin transporter. From Tatsumi et al ${ }^{29}$

\begin{tabular}{|c|c|c|}
\hline $\begin{array}{l}\text { Serotonin reuptake } \\
\text { inhibition group }\end{array}$ & Antidepressant & $\begin{array}{l}\text { Dissociation constant } \\
\text { (SEM) for serotonin } \\
\text { transporter (nM) }\end{array}$ \\
\hline \multirow[t]{4}{*}{ High } & Paroxetine & $0.13(0.01)$ \\
\hline & Clomipramine & $0.28(0.01)$ \\
\hline & Sertraline & $0.29(0.01)$ \\
\hline & Fluoxetine & $0.81(0.02)$ \\
\hline \multirow[t]{4}{*}{ Intermediate } & Imipramine & $1.4(0.03)$ \\
\hline & Fluvoxamine & $2.2(0.02)$ \\
\hline & Amitriptyline & $4.3(0.12)$ \\
\hline & Venlafaxine & $8.9(0.3)$ \\
\hline \multirow[t]{10}{*}{ Low } & Desipramine & $17.6(0.7)$ \\
\hline & Nortriptyline & $18(1)$ \\
\hline & Protriptyline & $19.6(0.5)$ \\
\hline & Amoxapine & $58(2)$ \\
\hline & Doxepin & $68(1)$ \\
\hline & Trimipramine & $149(6)$ \\
\hline & Trazodone & $160(20)$ \\
\hline & Nefazodone & $200(20)$ \\
\hline & Maprotiline & $5800(200)$ \\
\hline & Bupropion & $9100(300)$ \\
\hline
\end{tabular}

Table A2 Results of multivariate proportional hazards regression

\begin{tabular}{|c|c|c|c|}
\hline Variable & $\begin{array}{l}\text { Variable } \\
\text { estimate }\end{array}$ & SE & $\begin{array}{l}\text { Hazards ratio } \\
\quad(95 \% \mathrm{Cl})\end{array}$ \\
\hline $\begin{array}{l}\text { Serotonin reuptake inhibition } \\
\text { increased to next group }\end{array}$ & 0.10 & 0.04 & 1.10 (1.02 to 1.19$)$ \\
\hline Year entered study & -0.02 & 0.04 & 0.98 (0.91 to 1.05$)$ \\
\hline Age when entered study & 0.05 & 0.00 & 1.05 (1.04 to 1.06$)$ \\
\hline Female patient & -0.51 & 0.07 & 0.60 (0.53 to 0.68$)$ \\
\hline Diabetic patient & 0.23 & 0.08 & 1.26 (1.07 to 1.48$)$ \\
\hline $\begin{array}{l}\text { Patient had previous upper } \\
\text { gastrointestinal bleeding }\end{array}$ & 1.36 & 0.10 & 3.89 (3.17 to 4.77 ) \\
\hline $\begin{array}{c}\text { Patient taking non-steroidal } \\
\text { anti-inflammatory drugs }\end{array}$ & 1.05 & 0.08 & 2.85 (2.43 to 3.34$)$ \\
\hline Patient taking acetylsalicylic acid & 0.37 & 0.10 & 1.45 (1.18 to 1.77$)$ \\
\hline Patient taking glucocorticoid & 0.30 & 0.16 & 1.35 (0.99 to 1.84$)$ \\
\hline Patient taking anticoagulant & 0.64 & 0.13 & 1.90 (1.47 to 2.46$)$ \\
\hline $\begin{array}{l}\text { Patient taking } \mathrm{H}_{2} \text { receptor } \\
\text { antagonist or proton pump } \\
\text { inhibitor }\end{array}$ & 0.48 & 0.07 & 1.62 (1.40 to 1.87$)$ \\
\hline
\end{tabular}

Factor associated with increased risk of upper gastrointestinal bleeding when hazards ratio $>1$ and decreased risk when $<1$. Association significant at $\mathrm{P}=0.05$ level if $95 \%$ confidence interval excludes 1.

1 Li N, Wallen NH, Ladjevardi M, Hjemdahl P. Effects of serotonin on platelet activation in whole blood. Blood Coagulation Fibrinolysis 1997;8:517-23.

2 Ross SB, Aperia B, Beck-Friis J, Jansa S, Wetterberg L, Aberg A. Inhibition of 5-hydroxytryptamine uptake in human platelets by antidepressant agents in vivo. Psychopharmacology 1980;67:1-7. 
3 Alderman CP, Moritz CK, Ben-Tovim DI. Abnormal platelet aggregation associated with fluoxetine therapy. Ann Pharmacother 1992;26:1517-9.

4 Humphries JE, Wheby MS, VandenBerg SR. Fluoxetine and the bleeding time. Arch Pathol Lab Med 1990;114:727-8.

5 Wilmshurst PT, Kumar AV. Subhyaloid haemorrhage with fluoxetine. Eye 1996;10:141.

6 Aranth J, Lindberg C. Bleeding, a side effect of fluoxetine. Am J Psychiatry 1992;149:412.

7 Gunzberger DW, Martinez D. Adverse vascular effects associated with fluoxetine. Am J Psychiatry 1992;149:1751.

8 Ottervanger JP, Stricker BH, Huls J, Weeda JN. Bleeding attributed to the intake of paroxetine. Am J Psychiatry 1994;151:781-2.

9 Calhoun JW, Calhoun DD. Prolonged bleeding time in a patient treated with sertraline. Am J Psychiatry 1996;153:443.

10 Leung M, Shore R. Fluvoxamine-associated bleeding. Can J Psychiatry 1996;41:604-5.

11 De Abajo FJ, Rodriguez LA, Montero D. Association between selective serotonin reuptake inhibitors and upper gastrointestinal bleeding: population based case-control study. BMJ 1999;319:1106-9.

12 Garcia Rodriguez LA, Perez GS. Use of the UK general practice research database for pharmacoepidemiology. Br J Clin Pharmacol 1998;45: 419-25.

13 Jick H, Jick SS, Derby LE. Validation of information recorded on general practitioner based computerised data resource in the United Kingdom. BMJ 1991;302:766-8

14 Po AL. Antidepressants and upper gastrointestinal bleeding. BMJ 1999;319:1081-2.

15 Dickinson T, Malhi S, Painter S, Pyott J, Sawhney A. Association between SSRIs and upper gastrointestinal bleeding. Self treatment with non-steroidal drugs may be confounding factor. BMJ 2000:320:1406.

16 Dunn NR, Pearce GL, Shakir SA. Association between SSRIs and upper gastrointestinal bleeding. SSRIs are no more likely than other drugs to cause such bleeding. BMJ 2000;320:1405-6.

17 Williams D, Kelly A, Feely J. Association between SSRIs and upper gastrointestinal bleeding. Coprescription of antiulcer drugs with SSRIs is fairly common. BMJ 2000;320:1405.

18 Valvanne J, Juva K, Erkinjuntti T, Tilvis R. Major depression in the elderly: a population study in Helsinki. Int Psychogeriatrics 1996;8:437-43.

19 Oxman TE, Berkman LF, Kasl S, Freeman DHJ, Barrett J. Social support and depressive symptoms in the elderly. Am J Epidemiol 1992;135:356-68.

20 Kennedy GJ, Kelman HR, Thomas C. Persistence and remission of depressive symptoms in late life. Am J Psychiatry 1991;148:174-8.

21 Kennedy GJ, Kelman HR, Thomas C, Wisniewski W, Metz H, Bijur PE. Hierarchy of characteristics associated with depressive symptoms in an urban elderly sample. Am J Psychiatry 1989;146:220-5.

22 Griffiths RA, Good WR, Watson NP, O'Donnell HF, Fell PJ, Shakespeare JM. Depression, dementia and disability in the elderly. Br J Psychiatry $1987 ; 150: 482-93$

23 Berkman LF, Berkman CS, Kasl S, Freeman SRDH, Leo L, Ostfeld AM, et al. Depressive symptoms in relation to physical health and functioning in the elderly. Am J Epidemiol 1986;124:372-88.
24 Goldberg EL, Comstock GW, Hornstra RK. Depressed mood and subsequent physical illness. Am J Psychiatry 1979;136:530-4.

25 Blatchford O, Davidson LA, Murray WR, Blatchford M, Pell J. Acute upper gastrointestinal haemorrhage in west of Scotland: case ascertainment study. BMJ 1997;315:510-4.

26 Pahor M, Guralnik JM, Salive ME, Chrischilles EA, Brown SL, Wallace RB. Physical activity and risk of severe gastrointestinal hemorrhage in older persons. JAMA 1994;272:595-9.

27 Weil J, Langman MJ, Wainwright P, Lawson DH, Rawlins M, Logan RF, et al. Peptic ulcer bleeding: accessory risk factors and interactions with nonsteroidal anti-inflammatory drugs. Gut 2000;46:27-31.

28 Holmson H. Platelet secretion and energy metabolism. In: Kaplan, KL ed Hemostasis and thrombosis: basic principles and clinical practice. Philadelphia Lippincott, 1994:524-45.

29 Tatsumi M, Groshan K, Blakely RD, Richelson E. Pharmacological profile of antidepressants and related compounds at human monoamine transporters. Eur J Pharmacol 1997;340:249-58.

30 Canadian Pharmacists Association: Compendium of pharmaceuticals and specialties. Ottawa: Canadian Pharmacists Association, 1998.

31 Raiford DS, Gutthann SP, Rodriguez LAG. Positive predictive value of ICD-9 codes in the identification of cases of complicated peptic ulcer disease in the Saskatchewan hospital automated database. Epidemiology 1996;7:101-4.

32 Garcia RL, Jick H. Risk of upper gastrointestinal bleeding and perforation associated with individual non-steroidal anti-inflammatory drugs. Lancet 1994;343:769-72.

33 Greenland S, Rothman KJ. Introduction to stratified analysis. In: Rothman KJ, Greenland S, eds. Modern epidemiology. Philadelphia: Lippincott-Raven, 1998:253-80.

34 Rosner B. Hypothesis testing: person-time data. In: Rosner B, ed. Fundamentals of biostatistics. Pacific Grove, CA: Duxbury Press, 2000:677-741.

35 Allison PD. Estimating Cox-regression models with PROC PHREG. In: Survival analysis using the SAS system. Cary, NC: SAS Institute, 2000:11184.

36 Suissa S, Bourgault C, Barkun A, Sheehy O, Ernst P. Antihypertensive drugs and the risk of gastrointestinal bleeding. Am J Med 1998;105:230-5.

37 Pahor M, Guralnik JM, Furberg CD, Carbonin P, Havlik R. Risk of gastrointestinal haemorrhage with calcium antagonists in hypertensive persons over 67 years old. Lancet 1996;347:1061-5.

38 Grymonpre RE, Didur CD, Montgomery PR, Sitar DS. Pill count, self-report, and pharmacy claims data to measure medication adherence in the elderly. Ann Pharmacother 1998;32:749-54.

39 Carson JL, Strom BL, Schinnar R, Duff A, Sim E. The low risk of upper gastrointestinal bleeding in patients dispensed corticosteroids. Am J Med 1991;91:223-8.

40 Hennekens CH, Buring JE. Cohort studies. In: Mayrent SL, ed. Epidemiology in medicine. Boston: Little, Brown, 1987:153-77.

(Accepted 10 May 2001) 